\title{
ENDOTRACHEAL INTUBATION IN EMERGENCY- AN EXPERIENCE FROM EASTERN NEPAL
}

\author{
Rabin Bhandari ${ }^{1}$, Pramendra Prasad Gupta ${ }^{2}$, Rupak Bhandari ${ }^{3}$
}

${ }^{1}$ Additional Professor, Department of General Practice and Emergency Medicine, B. P. Koirala Institute of Health Sciences. ${ }^{2}$ Associate Professor, Department of General Practice and Emergency Medicine, B. P. Koirala Institute of Health Sciences. ${ }^{3}$ Assistant Professor, Department of General Practice and Emergency Medicine, B. P. Koirala Institute of Health Sciences.

\section{ABSTRACT}

\section{BACKGROUND}

Emergency Medical Care in Nepal is gradually improving with an increase in dedicated emergency departments with skilled manpower and availability of equipment, mostly in medical colleges and secondary to tertiary care centres.

\section{MATERIALS AND METHODS}

We conducted a cross-sectional descriptive study in a Medical University in the Eastern part of Nepal to find out the intubation success rates and the current practice/ method used to perform emergency intubations in our emergency.

\section{RESULTS}

215 intubated patients, median age 43 years with a male-to-female ratio of 1.26 were studied. Indications to intubate were failure to ventilate $(53.0 \%)$, airway protection $(36.7 \%)$ and expectant airway management including need for transport (10.2\%). The intubating doctors had experience of less than 6 months in 47 (21.86\%, 95\% CI 16.53 - 27.99), more than 6 months in 151 (70.23\%, 95\% CI 63.64 - 76.26) and senior operators in 17 (7.91\%, 95 CI 4.67 - 12.36) patients for 1st attempt intubations. Method used was rapid sequence intubation in 27 patients (12.56\%, 95\% CI $8.44-17.74)$, partial (sedation only) in 128 patients (59.52\%, 95\% CI 52.65 - 66.16) and crash intubation (no drugs) in 60 patients (27.91\%, 95\% CI 22.02 - 34.41). Urgent cases had more chances of intubation without use of any drugs ( $<<0.001)$. Midazolam was the drug used most frequently. Suxamethonium was the only muscle relaxant used. Intubation was successful at first attempt in 164 patients (76.28\%, 95\% CI 70.02 - 81.80), second attempt in 33 patients $(15.35 \%, 95 \%$ CI 10.81 - 20.87) and third attempt in 18 patients (8.37\%, 95\% CI 5.04 - 12.91). More experienced doctors had a better chance for success in the $1^{\text {st }}$ attempt $(n=215, p=0.003$, Fisher's exact test). Second attempt (30/33) and third attempt intubation (17/18) were undertaken by seniors. Oesophageal intubation was recorded in 27 cases and immediate haemodynamic instability in 4 cases.

\section{CONCLUSION}

Majority of intubations are performed by emergency doctors with success and acceptable complication rates. The proportion of patients undergoing intubation only under sedation is high.

\section{KEYWORDS}

Emergency, Endotracheal Intubation, Nepal.

HOW TO CITE THIS ARTICLE: Bhandari R, Gupta PP, Bhandari R. Endotracheal intubation in emergency- an experience from eastern Nepal. J. Evolution Med. Dent. Sci. 2017;6(85):5900-5903, DOI: 10.14260/jemds/2017/1283

\section{BACKGROUND}

Airway management skill is important for a doctor working in any field of clinical medicine. An appropriate method of controlling the airway and the safety of the procedure are the main concerns in emergency.[1] Tracheal intubation is the accepted gold standard for emergency department airway management for patients requiring a definitive airway. ${ }^{[2]}$ For an emergency physician, endotracheal intubation (ETI) is an essential skill.[3] With the advancement of emergency care, endotracheal intubations are occurring more frequently in emergency by doctors working in the department with more confidence and skill. Resident physicians primarily perform emergency intubation with acceptably high success rates.

'Financial or Other Competing Interest': None.

Submission 15-09-2017, Peer Review 10-10-2017,

Acceptance 16-10-2017, Published 23-10-2017.

Corresponding Author:

Dr. Rabin Bhandari,

Additional Professor,

Department of General Practice and Emergency Medicine,

B. P. Koirala Institute of Health Sciences,

Dharan, Nepal.

E-mail: rabin.bhandari@bpkihs.edu

DOI: $10.14260 /$ jemds $/ 2017 / 1283$
Overall, success rates are increasing with increasing seniority in emergency.[4,5] Junior doctors may feel more concerned about their "preparedness to intubate" with selfassessed deficits identified for this core competency required in critical patient care.[6] A study of interns also reported more variable rates to learn the skill compared to bag and mask ventilation. ${ }^{[7]}$

We did not find any research on intubation in emergency in Nepal. Nepal is a resource constraint setting. Resuscitation trolleys, equipment and drugs are still lacking in emergencies of many centres of Nepal.[8] But the scenario is improving, both in terms of skilled manpower and equipment. Many hospitals around the country now have dedicated emergency ward/ department and staffs. The doctors working in our emergency are a heterogeneous group both in terms of educational background and experience in airway management. The experience ranges from one-year rotatory internship only (including anaesthesia and emergency) in newly recruited house officers (MBBS) to experienced house officers (MBBS) and junior residents (MD trainee) with more experience and skill. The junior doctors are supervised by senior residents/ consultants of the Department of General Practice and Emergency Department. 
This study was done to find out the intubation success rates and the current practice/ method used to perform emergency intubations in our emergency.

\section{MATERIALS AND METHODS}

This is a descriptive cross-sectional study done at the emergency of BP Koirala Institute of Health Sciences (BPKIHS) over one year from $17^{\text {th }}$ Sept 2013 to $16^{\text {th }}$ Mar 2014. BPKIHS is a 763 bedded medical university with both undergraduate (MBBS) and postgraduate academic programmes. It is located in eastern part of Nepal. Department of General Practice and Emergency Medicine provides service to an average of 100 to 120 unsorted case mix in emergency per day.

The baseline variables studied were clinico-demographic profile of the patient and the intubation details including number of attempts at intubation, success rate, method of intubation and duration of work in emergency as a surrogate marker of intubating doctor's experience.

The patients were given triage score one to five using Australasian triage score (ATS), one being the most urgent. The patients were allocated definitive areas of management by the triage nurse. The doctors on duty made decisions regarding the need for intubation. Other variables recorded were post intubation duration of stay with ET tube in situ and outcome of patients recorded as mortality in emergency, extubation in emergency, admission to the hospital/ ICU and referrals for admission.

Any attempt at laryngoscopy without successful tracheal intubation was considered an unsuccessful attempt. Subsequent intubation attempts were recorded. Tracheal intubation was confirmed clinically by auscultation. The method of intubation was categorised as rapid sequence intubation (RSI, use of induction agent and muscle relaxant), partial (use of sedation/ induction agent, but no muscle relaxant) and crash intubation (urgent) when no drug to facilitate intubation was used. The intubating doctor's experience was classified into less than six months' experience in emergency, more than six months' experience in emergency and senior operators (senior residents and consultants working in emergency).

The study observed the practice of intubation and did not influence the managing doctor's decision. The decision to resuscitate the patient including intubation was always with consent, empathy and discussion as far as time allowed as is the practice of our department at present. The researchers did not participate in the method or the decision to intubate and the patients under direct care of researchers were excluded.

Data was recorded and analysed using Microsoft Excel 7, SPSS 11.5 version and EPI Info Version 7. Data was presented as tables, graphs and explanations. Mean with standard deviation (SD), median with interquartile range (IQR) and percentages were calculated. Chi-square and Fisher's exact tests were used to test association between different variables. Kruskal-Wallis test was used for non-parametric variables. Confidence interval was set at 95\%. Test was considered significant at $5 \%$.

\section{RESULTS}

A total of 215 intubated patients were included in the study. The median age of the patients was 43 years (IQR, $22-60$, Range 0 - 92) with a male-to-female ratio of 1.26 . Categorised by triage score, 38 patients $(17.67 \%, 95 \%$ CI $12.82-23.44)$ were labelled as triage score 1 (ATS), 165 patients $(76.74 \%$, 95\% CI $70.52-82.22$ ) as ATS 2 and 11 patients (5.12\%, 95\% CI 2.58 - 8.97) as ATS 3. There was a single patient intubated in ATS 4 and none in ATS 5. Trauma comprised $5.1 \%$ in this intubated population group. Other diagnostic classifications were poisoning including venoms $(17.2 \%)$, infections and sepsis (34\%) and other varied non-infectious conditions (stroke, asthma, chronic liver disease, etc.) leading to acute decompensation (43.7\%). The indications for intubations as listed by intubating doctors were failure to ventilate (53.0\%), airway protection $(36.7 \%)$ and anticipation of airway compromise and referral (10.2\%). The intubating doctors had experience of less than 6 months in 47 patients $(21.86 \%$, $95 \%$ CI 16.53 - 27.99), more than 6 months in 151 patients (70.23\%, 95\% CI $63.64-76.26)$ and senior operators in 17 (7.91\%, 95 CI $4.67-12.36)$ on $1^{\text {st }}$ attempt intubations.

\section{Methods used for First Attempt Intubation}

The method used was RSI in 27 patients $(12.56 \%, 95 \%$ CI 8.44 - 17.74), partial in 128 patients $(59.52 \%, 95 \%$ CI 52.65 $66.16)$ and crash intubation in 60 patients $(27.91 \%, 95 \% \mathrm{CI}$ 22.02 - 34.41). Time period and ATS were used as surrogate markers of urgency of intubation and compared against method. The average time to intubate was 10 minutes (IQR, 5 to 72) for crash intubation, 60 minutes (IQR, 20-165) for RSI and 70 minutes (IQR, 15 to 323.75) for partial method $(\mathrm{n}=215, \mathrm{p}<0.001$, Kruskal-Wallis). Crash intubation was performed more frequently in more urgent cases by triage category as well (ATS 1 and 2). RSI was undertaken more frequently by experienced doctors (Table 1 ).

\begin{tabular}{|c|c|c|c|c|}
\hline & $\begin{array}{c}\text { RSI } \\
(n=27)\end{array}$ & $\begin{array}{c}\text { Partial } \\
(n=128)\end{array}$ & $\begin{array}{c}\text { Crash } \\
(n=60)\end{array}$ & P-value \\
\hline $\begin{array}{c}\text { ATS1 } \\
(n=38)\end{array}$ & $1(2.6 \%)$ & $13(34.2 \%)$ & $24(63.2 \%)$ & \multirow{4}{*}{$<0.001 \dagger$} \\
\hline $\begin{array}{c}\text { ATS2 } \\
(n=165)\end{array}$ & $23(13.9 \%)$ & $108(65.5 \%)$ & $34(20.6 \%)$ & \\
\hline $\begin{array}{c}\text { ATS3 } \\
(n=11)\end{array}$ & $2(18.2 \%)$ & $7(63.6 \%)$ & $2(18.2 \%)$ & \\
\hline $\begin{array}{l}\text { ATS4 } \\
(n=1)\end{array}$ & $1(100 \%)$ & $0(0.0 \%)$ & $0(0.0 \%)$ & \\
\hline $\begin{array}{c}\text { Experience } \\
<6 \text { months } \\
(\mathrm{n}=47)\end{array}$ & $2(4.3 \%)$ & $31(66 \%)$ & $14(29.8 \%)$ & \multirow{3}{*}{$0.006 \dagger$} \\
\hline $\begin{array}{c}\text { Experience }> \\
6 \text { months } \\
(\mathrm{n}=151)\end{array}$ & 18 (11.9\%) & $92(60.9 \%)$ & $41(27.2 \%)$ & \\
\hline $\begin{array}{l}\text { Senior } \\
\text { operator } \\
(n=17)\end{array}$ & 7 (41.2\%) & $5(29.4 \%)$ & 5 (29.4\%) & \\
\hline
\end{tabular}

† Fisher Exact Test

\section{Intubation Success}

The average number of intubation per patient was 1.32 (SD 0.62). Intubation was successful at first attempt in 164 patients $(76.28 \%, 95 \%$ CI $70.02-81.80)$, second attempt in 
33 patients $(15.35 \%, 95 \%$ CI $10.81-20.87)$ and third attempt in 18 patients $(8.37 \%, 95 \%$ CI $5.04-12.91)$.

For first attempt successful intubation $(n=164)$, the experience of intubating doctors was less than six months in 27 patients $(16.46 \%, 95 \%$ CI $11.14-23.04)$, more than 6 months in 123 patients $(75.00 \%, 95 \%$ CI $67.65-81.42)$ and more senior operators in 14 patients $(8.54 \%, 95 \%$ CI 4.75 13.91). More experienced doctors had a better chance for success in the $1^{\text {st }}$ attempt $(n=215, p=0.003$, Fisher's exact test) (Table 2). For first attempt success $(n=164)$, the number of patients intubated by RSI was $22(13.41 \%$, 95\% CI 8.60 - 19.60), intubated by partial was 95 (57.93\%, $95 \mathrm{CI}$ 49.98 - 65.58) and intubated by crash was 47 (28.66, 95\% CI 21.88 - 36.23). The method of intubation did not show an association with success in the $1^{\text {st }}$ attempt $(n=215, p=0.639$, Chi-square) (Table 2).

\begin{tabular}{|c|c|c|c|}
\hline & $\begin{array}{c}\text { Success at } 1^{\text {st }} \\
\text { Attempt } \\
(n=164)\end{array}$ & $\begin{array}{c}\text { No Success at } 1^{\text {st }} \\
\text { Attempt } \\
(\mathrm{n}=51)\end{array}$ & $P$ value \\
\hline $\begin{array}{c}\text { Experience less } \\
\text { than } \\
6 \text { months } \\
(n=47)\end{array}$ & 27 (57.4\%) & $20(42.6 \%)$ & \multirow{3}{*}{$0.003 \dagger$} \\
\hline $\begin{array}{c}\text { Experience more } \\
\text { than } \\
6 \text { months } \\
(n=151)\end{array}$ & $123(81.5 \%)$ & $28(18.5 \%)$ & \\
\hline $\begin{array}{c}\text { Senior operators } \\
(\mathrm{n}=17)\end{array}$ & $14(82.5 \%)$ & $3(17.6 \%)$ & \\
\hline RSI (n= 27) & $22(81.5 \%)$ & $5(18.5 \%)$ & \multirow{3}{*}{$0.639 \ddagger$} \\
\hline Partial $(\mathrm{n}=128)$ & $95(74.2 \%)$ & $33(25.8 \%)$ & \\
\hline $\operatorname{Crash}(\mathrm{n}=60)$ & $47(78.3 \%)$ & $13(21.7 \%)$ & \\
\hline
\end{tabular}

$†$ Fisher Exact Test, $\neq$ Chi-Square Test

Successful intubation in second attempt $(n=33)$ was done by doctors with less than six months' experience in 3 patients (11.43\%, 95\% CI 3.20 - 26.74), doctors with more than six months' experience in 20 patients $(60.00 \%, 95 \%$ CI 42.11 $76.13)$ and senior operators in 10 patients $(28.57 \%, 95 \% \mathrm{CI}$ $14.64-46.30$ ).

Successful intubation in third attempt $(n=18)$ was done by doctors with less than six months' experience in 1 patient (7.00\%, 95\% CI 0.18 - 33.8), doctors with more than six months' experience in 10 patients $(57.27 \%$, 95\% CI 28.8 $82.3)$ and senior operators in 7 patients $(35.73 \%, 95 \% \mathrm{CI}$ 12.7 - 64.8).

\section{Complications, Duration of Stay and Outcome}

Oesophageal intubation was noted in 27 cases (2 RSI, 19 partial, 6 crash). Haemodynamic instability within 15 minutes of intubation requiring CPR was seen in 4 cases.

The average length of stay post intubation in emergency was 240 minutes (IQR, 120 - 570, Range 5 - 5760); 12 cases were extubated in emergency and admitted to ward. The median time of stay in emergency for these cases was 347 minutes (IQR, 180 - 3960, Range 60 - 5760); 100 cases were admitted in ICU or referred for the same; 50 (23.3\%) cases were admitted to ward, 37 (17.2\%) cases left against medical advice and 66 (30.7\%) cases died during emergency stay.

\section{DISCUSSION}

Endotracheal intubation is one of the preferred methods of airway management in emergency and critical care. It allows a definitive and protected airway, but has its antecedent complications. ${ }^{[5,9,10]}$ In emergency departments around the world intubations are being performed with increasing skills, methods and acceptable success rates. Residency programs and specialist physicians in the emergency department have contributed to this. $[4,5,11,12]$ Compared to established emergency departments, the emergency departments in Nepal are evolving. Our residents are trainee for general practice and emergency medicine degree. The house officers are pre-residency doctors and include new recruits to more experienced doctors, but the maximum exposure in emergency is for one year in general. Majority of $1^{\text {st }}$ attempts were carried out by doctors who have more than 6 months' experience. A change in hands was generally noticed to more senior doctors with the failure of $1^{\text {st }}$ attempt. Goto et al also noted similar practice in emergency, illustrative of the practice of an evolving emergency medicine care with the dual purpose of skill enhancement of both juniors and seniors, ${ }^{[4]}$ while giving optimum patient care in airway management.

Intubation in emergency can be difficult with a previously unknown patient.[4] Rapid sequence intubation is the preferred method and widely gaining acceptance; however, other method of intubation without use of muscle relaxants and "crash intubation" without use of any drugs are also reported.[4,5,11,12] A muscle relaxant should be used with caution if significant difficulty is anticipated.[13] The experience and comfort level of operator could also be a factor governing the choice of method and drug. In contrast to the study by Sagarin et al who reported $78 \%$ initial attempt by RSI, the first method was RSI in only $12 \%$ cases in our study. Majority of rapid sequence intubations were undertaken by more senior operators in our study and sedation facilitated intubation were mostly undertaken by more junior doctors $(\mathrm{p}=0.006)$. No drugs were used in $28 \%$. The group of patients intubated without drugs were mostly performed within a short time frame of presentation (10 minutes) and triage category, one which suggests more urgent and time constrained cases. The practice of intubation by doctors with sedation or minimal drugs could be reflective of difficult airway patient groups including trauma, need of urgent CPR or resource constraints including lesser number of skilled operators or drug cost and provision system.

The success rate for $1^{\text {st }}$ attempt intubation was 76\% (57\% for juniors and $82 \%$ for seniors) compared to $48 \%$ to $72 \%$ across first to fifth year residency experience ${ }^{[1]}$ and $72 \%$ to $88 \%$ in another study. ${ }^{[3]}$ The success rate for RSI was slightly higher $(81 \%)$ compared to other methods $(74 \%$ and $78 \%)$, although lesser number of people were intubated by this method. This shows an area identified for improvement in our emergency. The trend compares well to post graduate trainee success rate of $60 \%$ to $65 \%{ }^{[1]}$ and $72 \%$ to $85 \%,{ }^{[3]}$ across seniority levels, both favouring RSI. In other studies that primarily targeted rapid sequence intubations, Bair et al[12] showed that among 207 failed first course intubation, $18 \%$ and $14 \%$ intubations were by sedation only or use of no drugs respectively. He also showed that intubation by RSI is a preferred method both as a first and a rescue measure and 
has a high success rate. Tayal et al reported $80 \%$ success rate for the RSI method as primary method.

The longest duration of stay in emergency with intubation was for 4 days. Typical of our current practice, these patients are generally ventilated manually by their well-wishers (patient party). As a primary resuscitation manoeuvre, intubation saves life and some patients improve to extubate in the emergency itself (18 in this study). Especially, in acute reversible conditions like snake bites with neuroparalysis and other poisoning it is highly gratifying to emergency physicians. As far as the resource allocations allow, this also suggests the need to increase the facilities for optimal care to critically ill patients in emergency and in critical care areas of the hospital.

This research has allowed us to identify the current practice of endotracheal intubation and identify the areas of improvement. A focus on teaching intubating skill "on the job" and during medical school teaching may help the doctors to master the skill that is lifesaving.

\section{CONCLUSION}

Majority of intubations are performed by emergency doctors with success and acceptable complication rates. The proportion of patients undergoing intubation only under sedation is high and a shift to rapid sequence intubation which is gold standard is desirable. The time for patient's shift to definitive/ ongoing care is variable and patients are manually ventilated during the period. Skill enhancement and training on safe intubation practice would be helpful.

\section{Authors' Contributions}

Rabin Bhandari conceived the idea, contributed to design of the study, sample recruitment, analysis and interpretation of data, literature review and manuscript preparation.

Rupak Bhandari contributed to sample recruitment, analysis and interpretation of data, literature review and manuscript preparation.

Pramendra Prasad Gupta contributed to design of study, analysis and critically reviewed manuscript.

All the authors approved the final manuscript.

\section{ACKNOWLEDGEMENTS}

We thank Dr. Sudhir Dev and Dr. Manoj Lamsal for their help with sample collection and preliminary data record and our Head of Department and other doctors from emergency for their support.

\section{REFERENCES}

[1] Choi YF, Wong TW, Lau CC, et al. A study of orotracheal intubation in emergency departments of five district hospitals in Hong Kong. Hong Kong J Emerg Med 2003;10(3):138-45.
[2] Stevenson AGM, Graham CA, Hall R, et al. Tracheal intubation in the emergency department: the Scottish district hospital perspective. EMJ 2007;24(6):394-7.

[3] Clark TR, Brizendine EJ, Milbrandt JC, et al. Impact of an anesthesiology rotation on subsequent endotracheal intubation success. Journal of Graduate Medical Education 2013;5(1):70-3.

[4] Goto Y, Watase H, Brown CA, et al. Emergency airway management by resident physicians in Japan: an analysis of multicentre prospective observational study. Acute Medicine \& Surgery 2014;1(4):214-221.

[5] Tayal VS, Riggs RW, Marx JA, et al. Rapid-sequence intubation at an emergency medicine residency: success rate and adverse events during a two-year period. Acad Emerg Med 1999;6(1):31-7.

[6] Ochsmann EB, Zier U, Drexler H, et al. Well prepared for work? Junior doctors' self-assessment after medical education. BMC Med Educ 2011;11:99.

[7] Komatsu R, Kasuya Y, Yogo H, et al. Learning curves for bag-and-mask ventilation and orotracheal intubation: an application of the cumulative sum method. Anesthesiology 2010;112(6):1525-31.

[8] Dahal S. Emergency medicine scenarios: where do we stand? Kathmandu Univ Med J 2006;4(15):398-400.

[9] Mort TC. Complications of emergency tracheal intubation: hemodynamic alterations--part I. J Intensive Care Med 2007;22(3):157-65.

[10] Mort TC. Emergency tracheal intubation: complications associated with repeated laryngoscopic attempts. Anesth Analg 2004;99(2):607-13.

[11] Sagarin MJ, Barton ED, Chng YM, et al. Airway management by US and Canadian emergency medicine residents: a multicenter analysis of more than 6,000 endotracheal intubation attempts. Ann Emerg Med 2005;46(4):328-36.

[12] Bair AE, Filbin MR, Kulkarni RG, et al. The failed intubation attempt in the emergency department: analysis of prevalence, rescue techniques, and personnel. J Emerg Med 2002;23(2):131-40.

[13] Mayglothling J, Duane TM, Gibbs M, et al. Emergency tracheal intubation immediately following traumatic injury: an Eastern Association for the Surgery of Trauma practice management guideline. J Trauma Acute Care Surg 2012;73(5 Suppl 4):S333-40. 